Aplicação de métodos físicos, químicos e biológicos na avaliação da qualidade das águas em áreas de aproveitamento hidroelétrico da bacia do Rio São Tomás, Município de Rio Verde - Goiás Sandro Morais Pimenta, Alfredo Palau Peña, Patrícia Silva Gomes

\title{
APLICAÇÃO DE MÉTODOS FÍSICOS, QUÍMICOS E BIOLÓGICOS NAAVALIAÇÃO DA QUALIDADE DAS ÁGUAS EM ÁREAS DE APROVEITAMENTO HIDROELÉTRICO DA BACIA DO RIO SÃO TOMÁS, MUNICÍPIO DE RIO VERDE - GOIÁS
}

\author{
Application Methods of Physical, Chemical and Biological Evaluation of the Quality of Water \\ in Areas of Use Hydroelectric Basin of Stream São Tomás, Rio Verde - Goiás
}

Sandro Morais Pimenta

Dbo Engenharia Ltda

Goiânia/Goiás - Brasil

moraisecologia@gmail.com

Alfredo Palau Peña

Dbo Engenharia Ltda

Goiânia/Goiás - Brasil

alfredo.palau@gmail.com

Patrícia Silva Gomes

Dbo Engenharia Ltda

Goiânia/Goiás - Brasil

patriciagomes.ambiental@gmail.com

Artigo recebido para publicação em 12/05/2009 e aceito para publicação em 12/11/2009

RESUMO: O potencial hídrico do país aliado às novas políticas de incentivo a reestruturação do potencial energético estimula a iniciativa privada para a produção/geração de energia em matrizes alternativas. Inserem-se neste contexto as Pequenas Centrais Hidrelétricas - PCHs, empreendimentos com menores custos de implantação e menores impactos socioambientais. Um dos requisitos legais para a implantação destes empreendimentos é a realização de estudos que demonstrem as análises das interações destes com o meio ambiente e as respectivas medidas de controle e mitigação dos impactos ambientais. Para tanto foi realizada a avaliação da qualidade das águas de trechos do rio São Tomás no município de Rio Verde no sudoeste goiano como parte dos estudos ambientais necessários para a instalação de quatro PCHs, em quatro pontos de aproveitamento hidrelétrico do rio. Buscou-se com esta avaliação delinear o perfil da qualidade da água deste curso de água anteriormente à instalação de empreendimentos de geração de energia elétrica. Para a avaliação foi utilizada a correlação entre diferentes métodos de análises de qualidade: a aplicação do protocolo de avaliação ecológica rápida, avaliação por bioindicadores coletados nos pontos de amostragem, análise físico-química e bacteriológica e a utilização de Índice de Qualidade de Água - IQA.

Palavras-chave: PCHs. Avaliação de Qualidade de Água. Bioindicadores. IQA.

ABSTRACT: The country's water potential allied to the new politics of incentive to the reorganization of the energy potential stimulates the private initiative for the production/generation of energy in alternative matrices. 
Aplicação de métodos físicos, químicos e biológicos na avaliação da qualidade das águas em áreas

de aproveitamento hidroelétrico da bacia do Rio São Tomás, Município de Rio Verde - Goiás

Sandro Morais Pimenta, Alfredo Palau Peña, Patrícia Silva Gomes

In this context are inserted the Small Hydroelectric Plants - SHP, enterprises with lower costs of implantation and minors socio-environmental impacts. One of the legal requirements for the implantation of these enterprises is the accomplishment of studies that demonstrate analyses of the interactions of these enterprises with the environment and the respective measures of control and mitigation of the environmental impacts. Therefore, it was executed the quality evaluation of the waters in fractions of the São Tomás River, in the city of Rio Verde at Goiás southwest, as part of the necessary environmental studies for the installation of four SHP, four points of the river hydropower exploitation. It was intended with this evaluation to define the profile of the water quality of this water course previously the installation. For the evaluation was used the correlation between different methods of quality analyses: the application of the protocol of fast ecological evaluation, evaluation by bioindicators collected at the sampling spots, physical-chemical and bacteriological analysis and use of Water Quality Index WQI.

Keywords: SHP. Evaluation of Water Quality. Bioindicators. WQI.

\section{INTRODUÇÃO}

No ano de 2001 o Brasil percebeu a fragilidade de seu setor energético a partir da crise conhecida como "crise do apagão", que afetou o fornecimento e a distribuição de energia elétrica do país ocasionando cortes e racionamento de energia para a população e para os setores produtivos, evidenciando problemas estruturais significativos e comprometedores do desenvolvimento industrial e econômico do país. Os reflexos da ausência de investimentos no setor de geração energética, fez com que medidas paliativas fossem tomadas pelo Estado no sentido de estimular a iniciativa privada a investir na matriz energética do país, incluindo investimentos em fontes de energia alternativas.

De acordo com o alto potencial hídrico do país as matrizes mais disponíveis para a geração de energia são aquelas derivadas de centrais hidroelétricas, tornando as Pequenas Centrais Hidrelétricas - PCHs bem atraentes, considerando que estas são uma recomendação internacional por se tratar de uma energia alternativa e mais limpa em comparação a outros tipos de geração de energia, como as usinas termoelétricas e nucleares.

No passado o país já havia realizado experiências de incentivo a essas pequenas matrizes e para retomar esta política de incentivo a implantação de PCHs, atualmente o governo criou um programa chamado
Programa de Incentivo às Fontes Alternativas de Energia Elétrica - Proinfa.

Conforme a resolução n ${ }^{\circ} 394$ de 04/12/1998 da ANEEL - Agência Nacional de Energia Elétrica, PCH - Pequena Central Hidrelétrica é toda usina hidrelétrica de pequeno porte cuja capacidade instalada seja superior a $1 \mathrm{MW}$ e inferior a $30 \mathrm{MW}$. Além disso, a área do reservatório deve ser inferior a $3 \mathrm{~km}^{2}$. Este tipo de hidrelétrica é utilizada principalmente em rios de pequeno e médio porte com potência hidráulica suficiente para movimentar as turbinas. As PCHs são instalações que resultam em menores impactos ambientais e se prestam à geração descentralizada.

Para a implantação de PCHs são necessários vários estudos nos contextos econômicos, técnicos e socioambientais, os quais baseiam uma implantação eficiente em relação às características do meio ambiente. Os órgãos regularizadores e fiscalizadores requerem a apresentação de estudos ambientais, que demonstram as análises das interações, impactos e medidas mitigadoras para implantação de empreendimentos, dentre estas análises inclui a avaliação de qualidade de água das drenagens. Diante da simplicidade da PCH foi estabelecida a Resolução CONAMA n 279/ 2001, que define o RAS - Relatório Ambiental Simplificado, para a implantação das PCHs, ao invés do EIA/ RIMA, que é um estudo ambiental mais complexo e de longo prazo. 
Aplicação de métodos físicos, químicos e biológicos na avaliação da qualidade das águas em áreas de aproveitamento hidroelétrico da bacia do Rio São Tomás, Município de Rio Verde - Goiás Sandro Morais Pimenta, Alfredo Palau Peña, Patrícia Silva Gomes

A avaliação de qualidade das águas das drenagens superficiais faz parte do escopo destes estudos e é um instrumento importante da gestão ambiental. Ela consiste, basicamente, na realização do diagnóstico dos aspectos qualitativos e quantitativos das águas, visando à produção de informações e dados necessários para o monitoramento ambiental das áreas de influência dos empreendimentos que desenvolvam atividades potencialmente impactantes ao meio ambiente. A avaliação da qualidade ambiental de corpos hídricos é destinada às diversas instâncias legais pertinentes, bem como à comunidade científica e ao público em geral.

A qualidade da água pode ser alterada por causas naturais que ao longo do tempo levam os ecossistemas aquáticos a incorporarem diferentes substâncias, sem nenhuma contribuição antrópica, mas que podem afetar a sua constituição e as finalidades de seu uso. Entretanto, outros materiais lançados nos corpos hídricos pelas atividades humanas comprometem seriamente a qualidade das águas.

A resolução 357/2005 do CONAMA determina que o conjunto de parâmetros de qualidade de água selecionado para subsidiar a avaliação de um corpo hídrico deverá ser monitorado periodicamente, considerando também os parâmetros para os quais haja suspeita de presença ou alteração de determinados componentes que indicam alterações prejudiciais ao meio ambiente. Os resultados do monitoramento deverão ser analisados estatisticamente e as incertezas de medição devem ser consideradas.

\section{OBJETIVO}

O objetivo do trabalho foi realizar a avaliação da qualidade das águas na bacia do rio São Tomás no município de Rio Verde, no Estado de Goiás, em pontos indicados para aproveitamento hidrelétrico por meio de PCHs conforme Despacho daANEEL 249 de fevereiro de 2007. Tal avaliação busca traçar o perfil de qualidade das águas na região. Foi utilizada a correlação entre diferentes métodos de análises de qualidade sendo elas: a aplicação do protocolo de avaliação ecológica rápida, avaliação por bioindicadores nos pontos de amostragem, análise físico-química e bacteriológica e a utilização de Índice de Qualidade de Água da Companhia de Tecnologia de Saneamento Ambiental - IQA/CETESB.

\section{CARACTERIZAÇÃO DAÁREAAVALIADA}

Os Pontos de Aproveitamento Hidrelétrico PAH estão na região do município de Rio Verde, no sudoeste do Estado de Goiás (FIG. 1). O município possui uma área de $8.388,295 \mathrm{~km}^{2}$, e população de 158.818 habitantes, dista da capital do Estado aproximadamente $238 \mathrm{~km}$. As coordenadas de sua área central são $17^{\circ} 47^{\prime} 52^{\prime \prime}$ e $50^{\circ} 55^{\prime} 40^{\prime \prime}$ e altitude em torno de 748 metros do nível do mar.

O rio São Tomás tem suas nascentes com elevação aproximada de 800 metros, é formado pelo Ribeirão da Abóbora e pelo ribeirão do Meio, na elevação aproximada de 650 metros. A partir desta confluência, o comprimento do trecho é de aproximadamente $70 \mathrm{~km}$, atingindo a foz com o rio Verde ou Verdão na elevação aproximada de 460 metros, apresentando um desnível natural total de cerca de 340 metros.

Em todo o seu curso, o rio São Tomás recebe a contribuição de diversos afluentes, destacando-se como principais o rio do Peixe pela margem direita, cuja foz encontra-se na elevação aproximada de 600 metros, e o ribeirão do Douradinho pela margem esquerda, cuja foz encontra-se na elevação aproximada de 530 metros.

Segundo a classificação de Kooeppen (1948) a região onde se inserem os quatro $\mathrm{PAH}$ possui clima tipo Aw tropical úmido, caracterizado por duas estações bem definidas: uma seca que corresponde ao outono e inverno, e a outra úmida com chuvas torrenciais correspondendo ao período de primavera e verão. A distribuição pluviométrica apresenta padrão típico da região centro oeste do Brasil e do domínio morfoclimático dos Cerrados, precipitação média anual na ordem de $1.300 \mathrm{~mm}$, concentrando-se principalmente nos meses de dezembro a março. Nos meses de junho e julho as precipitações são praticamente nulas. $\mathrm{Na}$ estação climatológica de Rio Verde, a temperatura média anual apresenta pequena variação sazonal: é de $22,5^{\circ} \mathrm{C}$, com os maiores valores em outubro, $23,8^{\circ} \mathrm{C}$, e os menores em junho e julho $\left(20,3^{\circ} \mathrm{C}\right.$ e $20^{\circ} \mathrm{C}$, respectivamente).

A bacia do rio São Tomás localiza-se na seção setentrional da Bacia Sedimentar do Paraná, abrangendo os municípios de Rio Verde e Santa Helena de Goiás. 
Aplicação de métodos físicos, químicos e biológicos na avaliação da qualidade das águas em áreas de aproveitamento hidroelétrico da bacia do Rio São Tomás, Município de Rio Verde - Goiás

Sandro Morais Pimenta, Alfredo Palau Peña, Patrícia Silva Gomes

Na região dos PAH encontram-se solos decorrentes da alteração do arenito, latossolo roxo, solos do tipo gley pouco-húmicos e solos aluvionares. Os solos do tipo latossolo roxo, originados do basalto, são solos minerais, profundos e muito profundos, acentuadamente drenados, friáveis, muito porosos e permeáveis, com baixa susceptibilidade à erosão. (GEOGOIÁS, 2003).

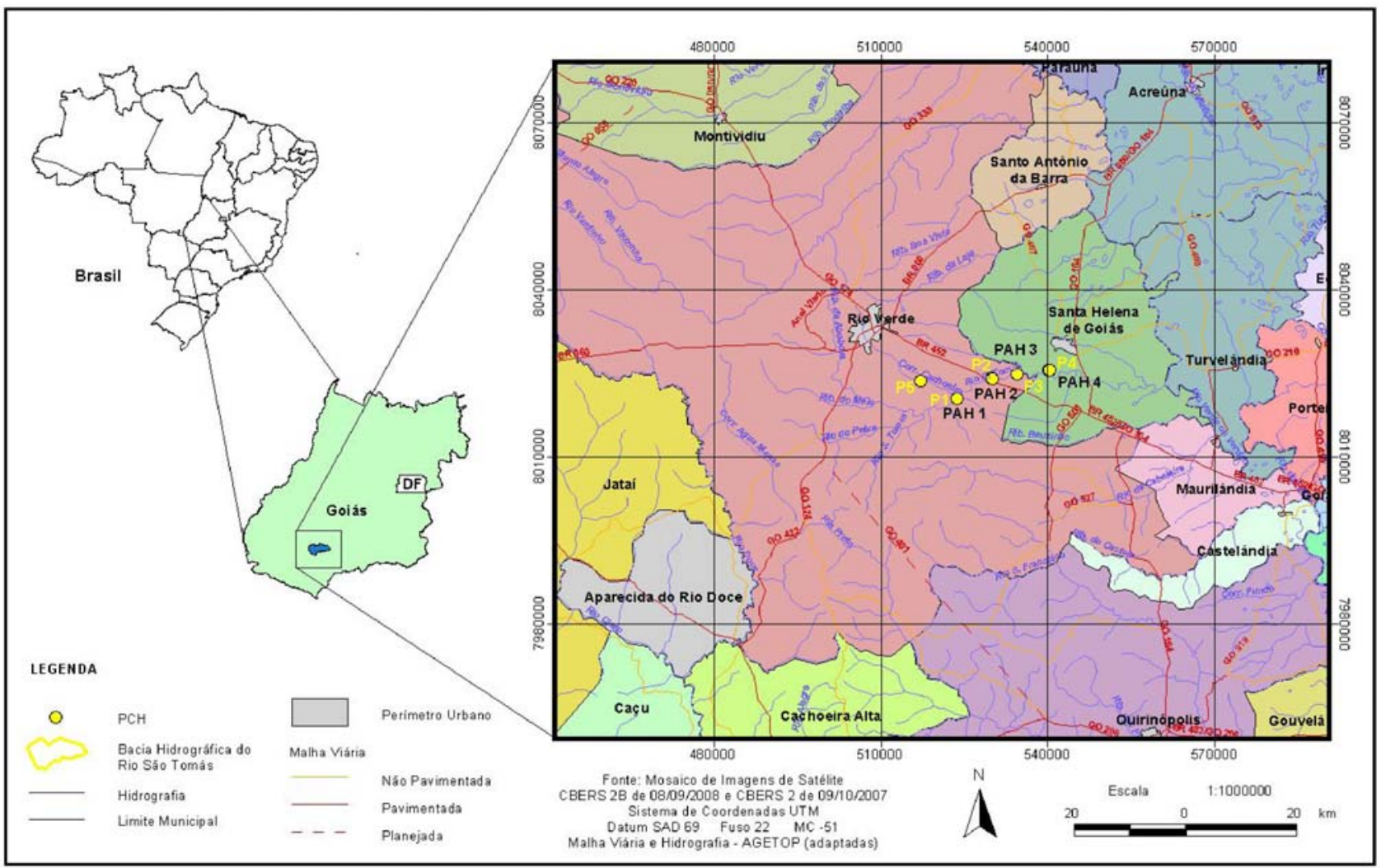

FIGURA 1: Localização da Bacia do Rio São Tomás e pontos de amsotragem, nas áreas de aproveitamento hidroeletrico.

\section{METODOLOGIAAPLICADA}

A amostragem e as análises foram realizadas no período chuvoso com coletas nos dias 17, 18, 19 de dezembro de 2008. A seleção dos pontos de amostragem ocorreu a partir da análise dos seguintes critérios: lançamentos de efluentes ao longo da drenagem, incidência de tributários na rede, possíveis fontes de poluição identificadas pela avaliação do uso e ocupação do solo e acessibilidade dos pontos selecionados.

Para o estudo foi escolhido um conjunto de métodos de avaliação de corpos de água aplicados nos 05 (cinco) pontos espacializados nas drenagens, buscando a correlação entre os resultados obtidos nos seguintes métodos aplicados: Protocolo de avaliação eco- lógica rápida modificada por Calisto et al (2001) da proposta original de Hannaford (1997) e da Agência de Proteção Ambiental de Ohio (EUA) EPA (1987). Para a aplicação do protocolo optou-se por adaptá-lo para as condições dos ambientes no sudoeste goiano conforme citado no item anterior.

Utilização de bioindicadores referentes à fauna de invertebrados bentônicos. Avaliação físico-química de qualidade de água com análise de 13 parâmetros de qualidade (Turbidez, Cor Verdadeira, Temperatura, $\mathrm{pH}$, Condutividade Elétrica - C.E, Sólidos Totais Dissolvidos - STD, Oxigênio Dissolvido - OD, Demanda Bioquímica de Oxigênio - DBO, Demanda Química de Oxigênio - DQO, Fósforo Total, Nitrogênio Total, Coliformes Totais, Coliformes Termotolerantes). Por fim optou-se pela utilização de um índice de qualidade 
Aplicação de métodos físicos, químicos e biológicos na avaliação da qualidade das águas em áreas de aproveitamento hidroelétrico da bacia do Rio São Tomás, Município de Rio Verde - Goiás Sandro Morais Pimenta, Alfredo Palau Peña, Patrícia Silva Gomes

de água no presente estudo, o IQA - Índice de Qualidade de Água da CETESB.

Após a aplicação dos métodos supracitados, buscou-se a correlação entre os resultados obtidos nos diferentes métodos com o objetivo de apurar a precisão e a própria avaliação de qualidade de água nas áreas dos PAH.

\subsection{Caracterização dos Pontos de Amostragem}

Foram determinados e caracterizados cinco (5) pontos de amostragem, na área dos $\mathrm{PAH}$, sendo 04 (quatro) pontos ao longo da drenagem do rio São Tomás e 01 (um) no córrego Cachoeirinha à montante dos primeiros quatro pontos.

Para esta avaliação foi considerada como área de influência direta a área referente ao PAH, ou seja, cada área de PAH é equivalente a um ponto de coleta. A área de influência indireta foi determinada considerando os pontos à jusante e à montante de cada ponto de coleta no trecho do curso de água avaliado.

Os pontos estão distribuídos e espacializados conforme a FIG. 2 a seguir:

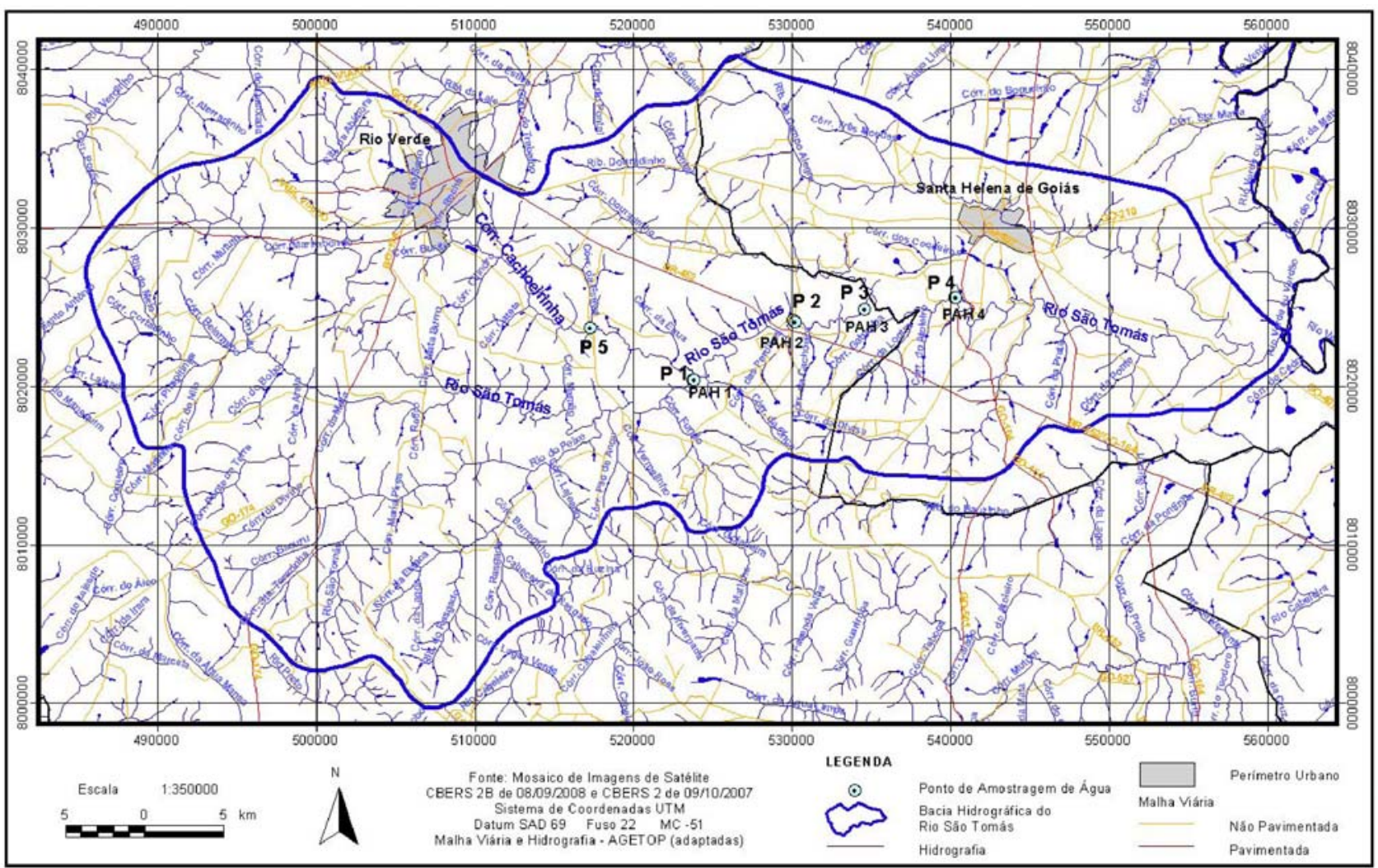

FIGURA 2: Bacia hidrográfica do rio São Tomás.

Ponto 01: Rio São Tomás (PAH 1), Coordenadas Geográficas: 1754'16.2”-5046’31.1”Altitude: 596 metros. Ponto de coleta com mata ciliar visualmente preservada, com mais de 50 metros de extensão e presença de plantação de soja a cerca de $100 \mathrm{~m}$ da margem do rio. As margens deste trecho do corpo de água apresentam estabilidade, sem evidências de erosões em seu entorno, profundidade de cerca de 70 cm com fundo formado predominantemente por cascalho, pedras e areia. A coleta de água, de invertebrados bentônicos e a aplicação do protocolo de avaliação ecológica foram realizadas abaixo da primeira queda de água (FIG. 3). 


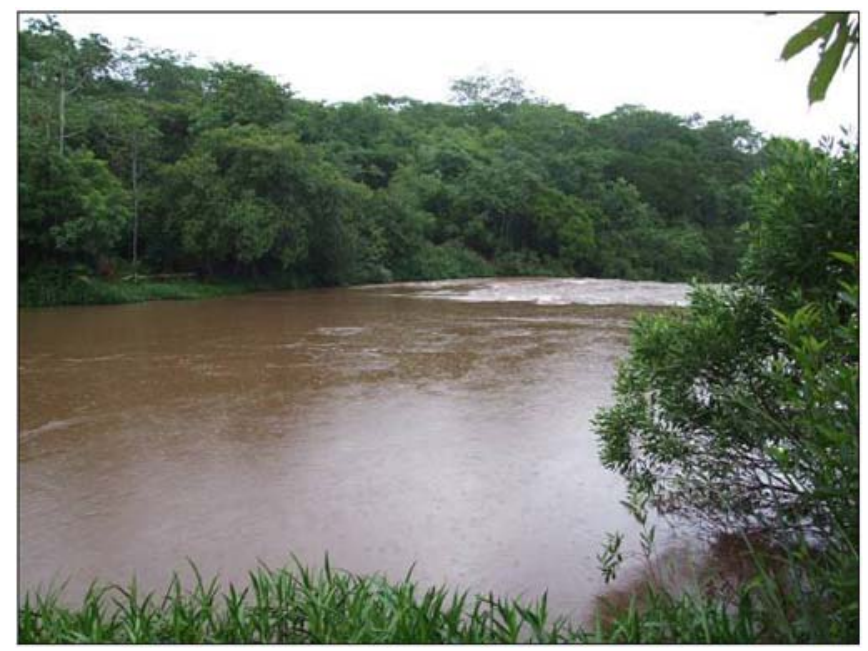

FIGURA 3: Foto do Rio São Tomás, ponto de amostragem 1 (PAH 1)

Ponto 02: Rio São Tomás (PAH 2), Coordenadas Geográficas: 1752'17.7”-5042’54.6”'Altitude: 572 metros. Ponto de coleta com entorno antropizado, com canalização de água à direita do curso de água por uma antiga PCH, e uma pousada à margem esquerda do rio. As margens do rio neste trecho são estáveis não apresentando evidências de erosões. O fundo do curso de água é formado por pedra e cascalho. A mata ciliar apresenta menos de $50 \%$ de vegetação nativa, evidenciando alterações antrópicas muito acentuadas. A coleta de água, de invertebrados bentônicos e a aplicação do protocolo de avaliação rápida foram realizadas na área da barragem da $\mathrm{PCH}$ existente (FIG. 4).

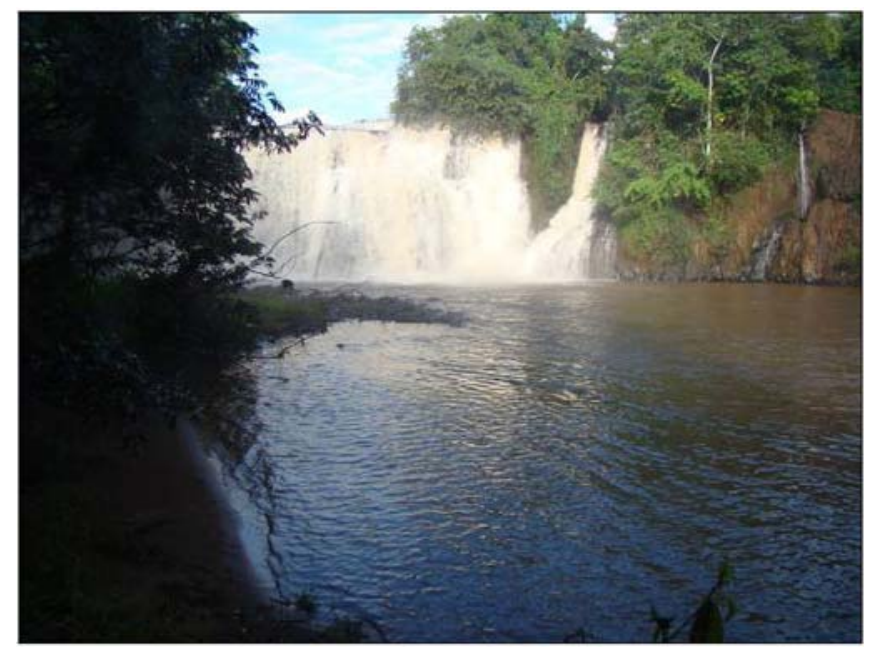

FIGURA 4: Rio São Tomás, fotos do entorndo do ponto de amostragem 2 (PAH 2)

Ponto 03: Rio São Tomás (PAH 3), Coordenadas Geográficas: 1751’41.9”-5040’55.0”Altitude: 561 metros. Ponto com vegetação marginal composta por mata de galeria reduzida para fins de atividades agropecuárias com gramíneas e vegetação ripária de baixa densidade. A profundidade do curso de água é de $70 \mathrm{~cm}$, com fundo composto por pedra, cascalho e um pouco de areia. As margens neste trecho são estáveis não apresentando evidencias de erosão. A coleta de água, de invertebrados bentônicos e a aplicação do protocolo de avaliação ecológica rápido foram realizadas à montante do ponto georreferenciado (FIG. 5). 


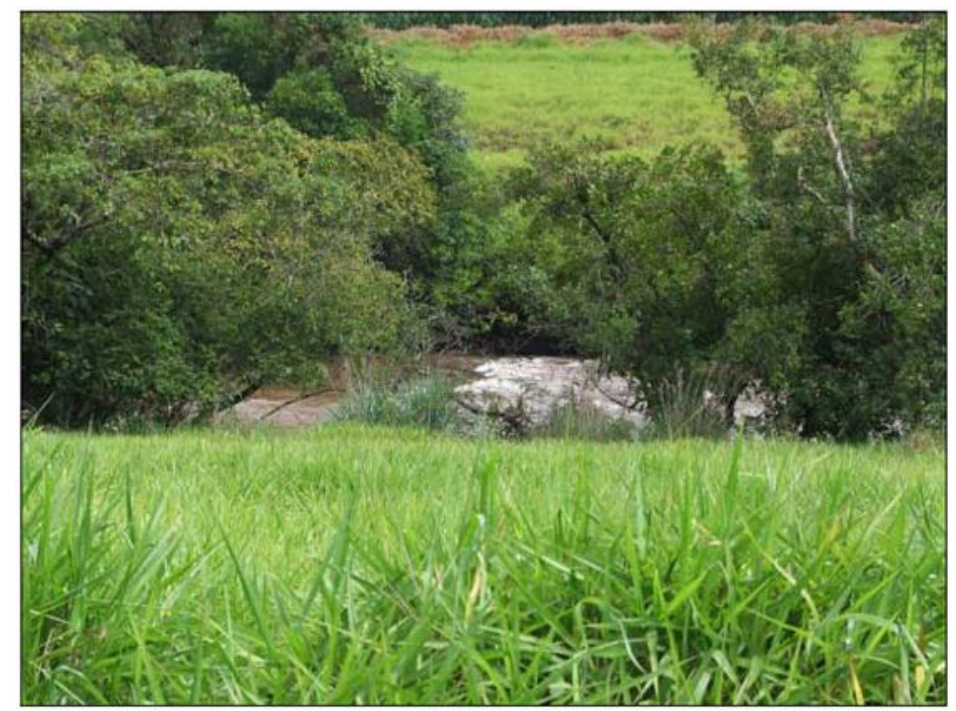

FIGURA 5: Rio São Tomás, ponto de amostragem 3, atividade agropastoril próxima a vegetação

Ponto 04: Rio São Tomás (PAH 4), Coordenadas Geográficas: 1751'26.0”- 50³7’10.0”'Altitude: 533 metros. Ponto com vegetação ripária composta de mata de galeria antropizada com menos de $15 \%$ de mata nativa, devido à ocupação de suas margens por pasto na primeira faixa de $50 \mathrm{~m}$ seguido de plantação de cana. À montante do ponto de coleta existe uma instalação de captação de água da SANEAGO para abastecimento público do município de Santa Helena de Goiás. O fundo é composto por pedras e cascalho, com deposição de cascalho em suas margens. Apresenta estabilidade em suas margens, não evidenciando princípios de erosão. Foram realizadas coleta de água, de invertebrados bentônicos e a aplicação do protocolo de avaliação ecológica rápido à montante do ponto georreferenciado (FIG. 6).

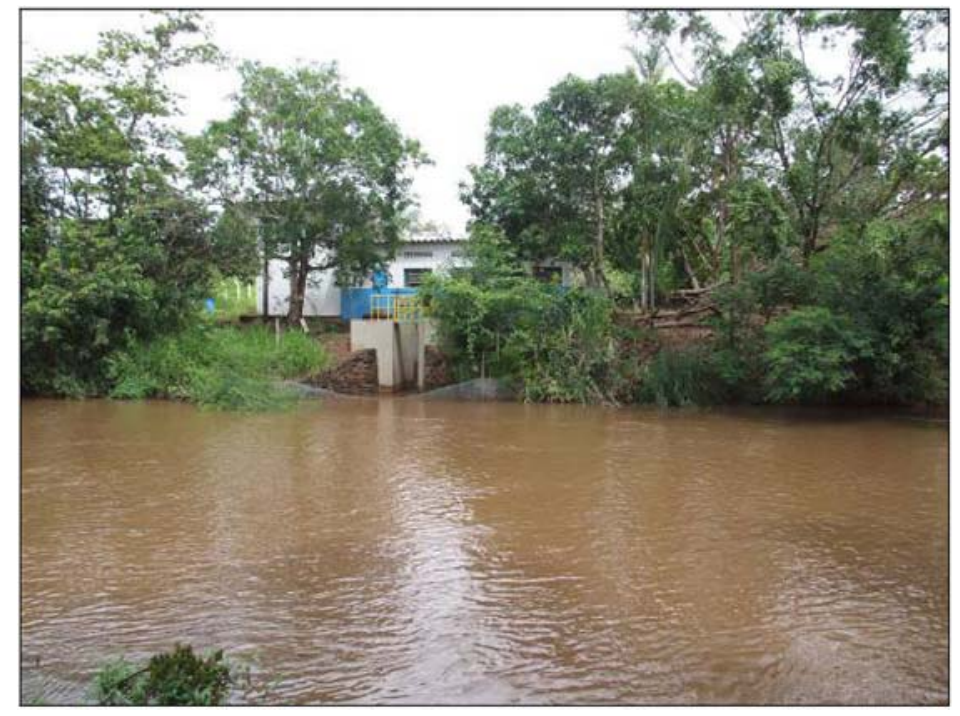

FIGURA 6: Rio São Tomás detalhe na captação de água da concessionaria Saneago à montante do ponto de coleta PAH 4

Ponto 05: Córrego Cachoeirinha, Coordenadas Geográficas: 1752’29.4”-5050’12.6”Altitude:
630 metros. Ponto de coleta próximo a uma ponte com presença de mata ciliar pouco densa com menos 
Aplicação de métodos físicos, químicos e biológicos na avaliação da qualidade das águas em áreas de aproveitamento hidroelétrico da bacia do Rio São Tomás, Município de Rio Verde - Goiás Sandro Morais Pimenta, Alfredo Palau Peña, Patrícia Silva Gomes

de $15 \mathrm{~m}$, córrego com profundidade média de $70 \mathrm{~cm}$ com fluxo intermediário, quase sem pedras expostas; substrato composto de areia, pedras e cascalho. Margens estáveis, não apresentando evidências de erosão. Corpo de água com odor característico de presença de efluentes domésticos e/ou industriais. A coleta de água, de invertebrados bentônicos e a aplicação do protocolo de avaliação ecológica rápida foram realizadas à montante e à jusante da ponte (FIG. 7).

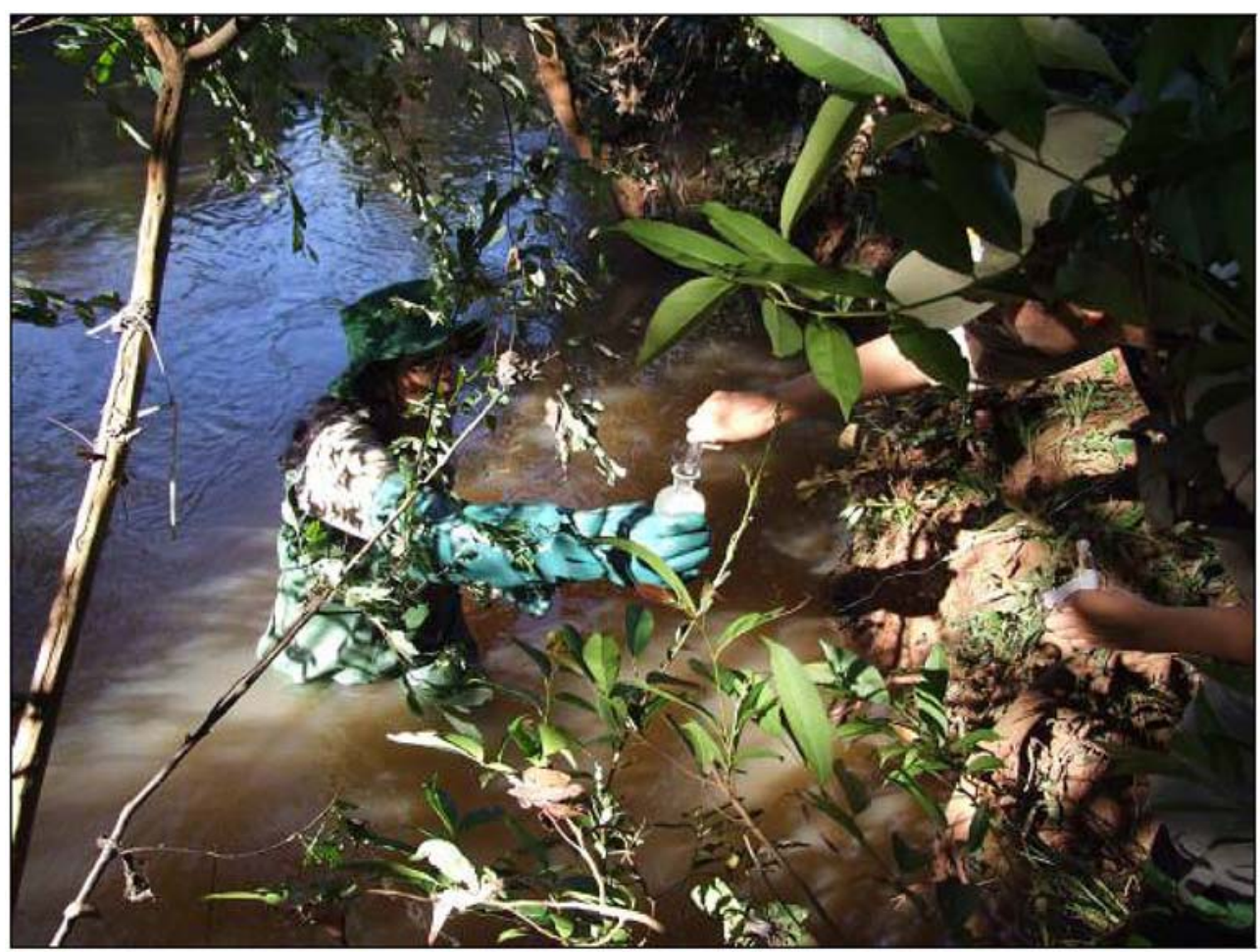

FIGURA 7: Coleta de água e bentos no Córrego Cachoeirinha, a montante de uma ponte.

\subsection{Protocolo de Avaliação Ecológica}

O protocolo de avaliação ecológica rápida aplicada nos pontos de amostragem foi utilizado para a complementação da caracterização da área nos trechos avaliados do rio São Tomás a fim de contribuir com a construção do diagnóstico ambiental e avaliação da qualidade das águas desta drenagem, bem como servir como base para futuros monitoramentos ambientais. O protocolo de avaliação é um método rápido que busca caracterizar amplamente o curso de água com parâmetros sedimentológicos, ecológicos e biológicos. Aplicado in-loco possibilita a contextualização do corpo hídrico com os usos do solo de seu entorno imediato e as alterações antrópicas existentes.
O método baseia-se na avaliação qualitativa de cursos de água atribuindo por meio de um protocolo valores numéricos referentes aos aspectos físicos e biológicos possibilitando a classificação destas áreas em: natural, alterado ou impactado, através da atribuição de pontuação para as áreas avaliadas.

Na primeira etapa do protocolo (questões $1 \mathrm{a}$ 10) o conjunto de parâmetros avaliado pode indicar: situação natural (4 pontos), situações levemente alteradas ( 2 pontos) e severamente alteradas ( 0 pontos).

Na segunda etapa do protocolo o conjunto de parâmetros avaliado pode indicar: situação natural (5 pontos), situações leve ou severamente alteradas, são respectivamente $3,2,0$ pontos. De forma sucinta os parâmetros avaliados no protocolo são apresentados a seguir (TAB. 1): 
Aplicação de métodos físicos, químicos e biológicos na avaliação da qualidade das águas em áreas de aproveitamento hidroelétrico da bacia do Rio São Tomás, Município de Rio Verde - Goiás Sandro Morais Pimenta, Alfredo Palau Peña, Patrícia Silva Gomes

TABELA 1: Parâmetros componentes do Protocolo de Avaliação Rápida

\begin{tabular}{cl|ll}
\hline \multicolumn{2}{c|}{ PARÂMETROS (Primeira Etapa) } & \multicolumn{2}{c}{ PARÂMETROS (Segunda Etapa) } \\
\hline $\mathbf{1}$ & $\begin{array}{l}\text { Tipos de ocupação das margens do corpo de água } \\
\text { (principal atividade) }\end{array}$ & $\mathbf{1 1}$ & Tipos de fundo (habitats) \\
$\mathbf{2}$ & $\begin{array}{l}\text { Erosão próxima e/ou nas margens do rio e } \\
\text { assoreamento em seu leito }\end{array}$ & $\mathbf{1 2}$ & Extensão de rápidos \\
$\mathbf{3}$ & Alterações Antrópicas & $\mathbf{1 3}$ & Freqüência de rápidos \\
$\mathbf{4}$ & Cobertura vegetal no leito & $\mathbf{1 4}$ & Tipos de substratos \\
$\mathbf{5}$ & Odor da água & $\mathbf{1 5}$ & Deposição de lama \\
$\mathbf{6}$ & Oleosidade da água & $\mathbf{1 6}$ & Depósitos sedimentares \\
$\mathbf{7}$ & Transparência da água & $\mathbf{1 7}$ & Alterações no canal do rio \\
$\mathbf{8}$ & Odor do sedimento (fundo) & $\mathbf{1 8}$ & Características do fluxo das águas \\
$\mathbf{9}$ & Oleosidade do fundo & $\mathbf{1 9}$ & Presença de mata ciliar \\
$\mathbf{1 0}$ & Tipo de fundo & $\mathbf{2 0}$ & Estabilidade das margens \\
& & $\mathbf{2 1}$ & Extensão de mata ciliar \\
- & $\mathbf{2 2}$ & Presença de plantas aquáticas \\
\hline
\end{tabular}

Fonte: Adaptado de Callisto et al, 2004-b.

A pontuação final dos parâmetros indica o nível de preservação das condições ecológicas dos trechos da drenagem avaliada. De 0 a 40 pontos representa trechos impactados, 41 a 60 pontos representam trechos alterados, acima de 61 pontos os trechos são considerados naturais.

O tempo necessário para a aplicação do protocolo nos trechos do rio São Tomás foi de cerca de 30 minutos para cada ponto de amostragem. O protocolo foi aplicado nos pontos espacializados ao longo do rio São Tomás e no córrego Cachoeirinha, nos mesmos pontos onde foram realizadas as amostragens para os parâmetros físicos químicos e para os bioindicadores (invertebrados bentônicos).

Os dados obtidos com a aplicação do protocolo foram analisados e tratados de acordo com a metodologia supracitada, apontando resultados que são discutidos mais adiante.

\subsection{Avaliação por Bioindicadores de Qualidade de Água}

Associada ao protocolo de avaliação ecológica rápida foi realizada a avaliação de bioindicadores de qualidade do ambiente. Os bioindicadores são espécies que a sua presença ou mesmo a sua ausência indicam o nível de preservação de habitats. As mudanças que ocorrem na estrutura das comunidades de bioindicadores variam de comunidades complexas e diversas com organismos próprios de águas limpas, intolerantes à poluição a comunidades simples e de baixa diversidade que apresentam organismos capazes de viver em águas contaminadas, tendo variações de acordo com os efeitos da contaminação doméstica e industrial.

Os bioindicadores amostrados foram espécies da fauna de invertebrados bentônicos coletados nos 05 pontos espacializados na área com um amostrador de Surber, acondicionados em frascos plásticos e fixado com álcool $80 \%$ para identificação e contagem dos táxons encontrados. A comunidade de invertebrados bentônicos são componentes importantes dos sedimentos de rios e lagos, sendo fundamentais para a dinâmica de nutrientes, a transformação de matéria e do fluxo de energia (CALLISTO et al, 2004-b) e a composição desta estrutura e sua tolerância aos sedimentos indicam a qualidade do ambiente no sucesso de colonização e estabelecimento das comunidades biológicas em ambientes lênticos ou lóticos.

Os invertebrados bentônicos como bioindicadores (CHALAR, 1994; CALLISTO et al, 2004a e b) e Monkolski et al (2006) neste estudo foram divididos em três grupos (segundo CALLISTO et al, 2004-b): organismos sensíveis ou intolerantes (representantes de Trichoptera, Plecoptera, Ephemeroptera), organismos tolerantes (representantes de Coleóptera, Heteroptera, Odonata) e organismos resistentes (Díptera, Oligochaeta). Já quanto ao Valor de Tolerân- 
Aplicação de métodos físicos, químicos e biológicos na avaliação da qualidade das águas em áreas

de aproveitamento hidroelétrico da bacia do Rio São Tomás, Município de Rio Verde - Goiás

Sandro Morais Pimenta, Alfredo Palau Peña, Patrícia Silva Gomes

cia à Poluição (VTP) segundo King (1993) onde estão ponderadas as famílias de insetos aquáticos variando de 0 a 10 e classificadas de intolerantes a poluição (VTP de 0 a 2), tolerantes a moderada poluição (VTP de 3 a 4) e alta tolerância a poluição (VTP e” 5).

\subsection{Análises Físico-Químicas de Água e IQA}

Para as análises físico-químicas de qualidade de água podem-se empregar equipamentos de campo e análises laboratoriais de amostras, aumentando o número de dados em poucos pontos de coleta distribuídos ao longo das drenagens, obtendo-se, dessa forma, uma precisão razoável de resultados, com um mínimo de despesas de material e operação.

A amostragem em questão foi realizada de acordo com a norma NBR 9898 e a Resolução do CONAMA n ${ }^{\circ} 357$ de 2005. A primeira fixa as condições exigíveis para a coleta e a preservação de amostras e de efluentes líquidos domésticos e industriais e de amostras de água, sedimentos e organismos aquáticos dos corpos receptores interiores superficiais. A segunda dispõe sobre a classificação dos corpos de água e diretrizes ambientais para o seu enquadramento, bem como estabelece as condições e padrões de lançamento de efluentes.

Para a avaliação físico-química da qualidade da água foram selecionados 13 parâmetros de qualidade (Turbidez, Cor Verdadeira, Temperatura, pH, Condutividade Elétrica - C.E, Sólidos Totais Dissolvidos - STD, Oxigênio Dissolvido - OD, Demanda Bioquímica de Oxigênio - DBO, Demanda Química de Oxigênio - DQO, Fósforo Total, Nitrogênio Total, Coliformes Totais, Coliformes Termotolerantes). As variações dos parâmetros representam o estado de qualidade da água nos pontos avaliados.

As análises dos parâmetros físico-químicos foram determinadas em laboratório seguindo os procedimentos do Standard Methods for the Examination of Water and Wastewater (SMWW), o Método da CETESB e a Análise Sensori. O laboratório responsável pelas análises dos parâmetros da amostragem foi o laboratório da AQUALIT Tecnologia em Saneamento SS LTDA, este possui Sistema de Gestão da Qualidade (SGQ), baseado na NBR ISSO/IEC 17025, documentado, implantado e mantido em adequação à norma.
Os resultados das variações quantitativas nos parâmetros físico-químicos e biológicos amostrados no período chuvoso foram tratados preliminarmente com testes da estatística descritiva paramétrica. Esses procedimentos baseiam-se nos trabalhos de Andreoli e Carneiro (2005), Carmo, Boaventura e Oliveira (2005), Pimenta (2008) e nas recomendações do CONAMA 357/05, sendo utilizados: a média harmônica da variação quantitativa, a freqüência absoluta, o desvio padrão (ó) dos valores obtidos nos pontos de amostragem e o coeficiente de variação.

Após o tratamento preliminar com a estatística descritiva optou-se pela aplicação de um índice de qualidade de água. Os índices de qualidade de água são importantes no acompanhamento da qualidade levando em conta que existem incertezas por detrás das variáveis que os compõem.

Para os pontos de amostragem na drenagem do São Tomás utilizou-se o índice de qualidade IQANSF, modificado pela CETESB, este é calculado pelo produto ponderado das notas atribuídas a 09 parâmetros de qualidade de água: 1) temperatura da amostra, 2) $\mathrm{pH}, 3$ ) oxigênio dissolvido, 4) demanda bioquímica de oxigênio (5 dias, $\left.20^{\circ} \mathrm{C}\right)$, 5) coliformes fecais, 6 ) nitrogênio total, 7) fosfato total, 8) sólidos totais e 9) turbidez. A seguinte equação é utilizada (equação 1):

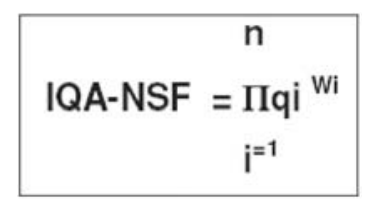

Onde: IQA-NSF - Índice de Qualidade das Águas, um número entre 0 e 100; qi - qualidade do iésimo parâmetro, um número entre 0 e 100, obtido da respectiva "curva média de variação de qualidade", em função de sua concentração ou medida; e wi peso correspondente ao i-ésimo parâmetro, um número entre 0 e 1 , atribuído em função da sua importância para a conformação global de qualidade, em que n é 9 , (equação 2):

$$
\sum_{i=1}^{n} w_{i}=1
$$


Aplicação de métodos físicos, químicos e biológicos na avaliação da qualidade das águas em áreas de aproveitamento hidroelétrico da bacia do Rio São Tomás, Município de Rio Verde - Goiás Sandro Morais Pimenta, Alfredo Palau Peña, Patrícia Silva Gomes

Na TAB. 2, encontram-se os parâmetros rela- tivos ao IQA com seus respectivos pesos.

TABELA 2: Parâmetros e pesos relativos do IQA.

\begin{tabular}{clc}
\hline Quat. & \multicolumn{1}{c}{ Parâmetros } & $\begin{array}{c}\text { Pesos } \\
\text { Relativos }\end{array}$ \\
\hline 1 & Oxigênio Dissolvido & 0,17 \\
2 & Coliformes Termotolerantes & 0,15 \\
3 & pH & 0,12 \\
4 & Demanda Bioquímica de Oxigênio & 0,10 \\
5 & Fósforo Total & 0,10 \\
6 & Temperatura & 0,10 \\
7 & Nitrogênio total & 0,10 \\
8 & Turbidez & 0,08 \\
9 & Sólidos Totais Dissolvidos & 0,08 \\
\hline
\end{tabular}

Fonte: CETESB (1997).

A classificação da qualidade da água segundo

CETESB apresentados na TAB. 3. o IQA CETESB é feita utilizando os critérios da

TABELA 3: Valores de quantificação e classificação para o IQA

\begin{tabular}{cc}
\hline \multicolumn{2}{c}{ Valor Qualificação } \\
\hline $80-100$ & Ótima \\
$52-79$ & Boa \\
$37-51$ & Aceitável \\
$20-36$ & Ruim \\
$0-19$ & Péssima \\
\hline \multicolumn{2}{c}{ Fonte: CETESB (1997). }
\end{tabular}

\section{RESULTADOS E DISCUSSÕES}

\subsection{Protocolo de Avaliação Ecológica}

A TAB. 4 abaixo representa a análise dos resultados levantados in loco com a aplicação do protocolo de avaliação ecológica utilizado nos pontos de amostragem das drenagens do rio São Tomás e córrego Cachoeirinha.

Os resultados da avaliação ecológica apresentaram condições naturais em quatro dos cinco pontos amostrados, indicando a conservação ambiental dos principais aspectos levantados pelo protocolo, como estabilidade das margens, presença de mata ciliar, ausência de erosões e de alterações no leito do rio São Tomás nos pontos P1, P2, P3 e P4. Vale ressaltar que o P1 referente ao local do PAH1 foi o ponto com maior pontuação, evidenciando qualidade do curso de água, de acordo com os critérios do método utilizado.

Somente o P5 referente ao córrego Cachoeirinha obteve pontuação indicando curso de água alterado, apresentando alterações em seu curso, presença de odores característicos de esgotos domésticos e/ou industriais e outros parâmetros com pontuação abaixo do considerado natural. 
Aplicação de métodos físicos, químicos e biológicos na avaliação da qualidade das águas em áreas de aproveitamento hidroelétrico da bacia do Rio São Tomás, Município de Rio Verde - Goiás

Sandro Morais Pimenta, Alfredo Palau Peña, Patrícia Silva Gomes

TABELA 4: Resultados dos parâmetros avaliados no protocolo

\begin{tabular}{|c|c|c|c|c|c|}
\hline PARÂMETROS & Ponto 1 & Ponto 2 & Ponto 3 & Ponto 4 & Ponto 5 \\
\hline Tipos de ocupação das margens & 4 & 0 & 2 & 2 & 2 \\
\hline Erosão próxima e/ou nas margens & 4 & 4 & 4 & 4 & 4 \\
\hline Alteracões antrópicas & 4 & 2 & 4 & 4 & 0 \\
\hline Cobertura vegetal no leito & 4 & 4 & 4 & 4 & 0 \\
\hline Odor da água & 4 & 4 & 4 & 4 & 2 \\
\hline Oleosidade da água & 4 & 4 & 2 & 4 & 4 \\
\hline Transparência da água & 4 & 2 & 2 & 4 & 4 \\
\hline Odor do sedimento (fundo) & 4 & 4 & 4 & 4 & 2 \\
\hline Oleosidade do fundo & 4 & 4 & 4 & 4 & 4 \\
\hline Tipo de fundo & 4 & 4 & 4 & 4 & 4 \\
\hline Tipo de fundo (habitats) & 5 & 3 & 3 & 2 & 5 \\
\hline Extensão de rápidos & 5 & 2 & 5 & 5 & 2 \\
\hline Freqüências de rápidos & 3 & 3 & 3 & 3 & 3 \\
\hline Tipos de substratos & 0 & 0 & 2 & 0 & 0 \\
\hline Deposição de lama & 5 & 5 & 5 & 5 & 3 \\
\hline Depósitos sedimentares & 5 & 5 & 5 & 2 & 3 \\
\hline Alterações no canal do curso & 5 & 3 & 5 & 5 & 3 \\
\hline Caracteristicas do fluxo das águas & 5 & 5 & 5 & 5 & 3 \\
\hline Presença de mata ciliar & 5 & 3 & 0 & 0 & 0 \\
\hline Estabilidade das margens & 5 & 5 & 5 & 5 & 5 \\
\hline Extensão da mata ciliar & 5 & 3 & 0 & 0 & 0 \\
\hline Presença de plantas aquáticas & 5 & 0 & 0 & 5 & 0 \\
\hline Pontuação & 93 & 69 & 72 & 75 & 53 \\
\hline Avaliação & Natural & Natural & Natural & Natural & Alterado \\
\hline
\end{tabular}

\subsection{Avaliação por Bioindicadores de Qualidade das Águas}

Os resultados obtidos na avaliação de bioindicadores segundo Callisto et al (2004-b) nos trechos estudados do rio São Tomás apontam a presença de espécies intolerantes nos pontos P1, P3 e P4 (TAB. 6). O maior número de espécies foi encontrado no P1, indicando neste ponto condições ambientais favoráveis para espécies sensíveis às alterações ambientais.

Os organismos tolerantes estão presentes nos quatro primeiros pontos, somente o P5 não apresentou estes bioindicadores. A presença dos organismos tolerantes aponta uma leve a moderada alteração no ambiente, porém com características ainda favoráveis para espécies mais tolerantes.

As espécies resistentes foram encontradas em todos os pontos de amostragem, com maior número de taxas nos pontos P1, P4 e P5. Vale ressaltar que o P5 apresentou somente espécies resistentes, indicando alterações antrópicas relevantes no córrego Cachoeirinha. Os resultados podem ser visualizados no TAB. 6.

Quanto ao Valor de Tolerância a Poluição (VTP) atribuído às famílias de invertebrados bentônicos segundo King (1993) o P1 está representado por uma comunidade com tolerância moderada a poluição (TAB. 5), e corrobora com os grupos mais intolerantes a tolerantes segundo Callisto et al (2004-b) e destacou também o P5 com famílias com VTP maiores que 5, muito tolerantes a poluição e ou resistentes. (TAB. 6).

A presença da maioria dos grupos taxonômicos das Ordens Ephemeroptera, Plecoptera e Trichoptera (EPT) nas amostragens de invertebrados bentônicos evidenciou ambientes com melhor qualidade ambiental. O P1 e P3 apresentaram 3 famílias dentro das duas Ordens Ephemeroptera e Trichoptera. A não ocorrência nos demais pontos pode estar relacionada ao período sazonal chuvoso onde estes grupos levam um tempo maior de colonização após um distúrbio (BISPO et al, 2001), as chuvas na véspera das amostragens.

As características de ambientes lóticos com corredeiras na maioria dos pontos amostrados (P1, P4, P5) podem ter evidenciado a abundância e ou riqueza da maioria dos táxons, onde, segundo Kikuchi \& Uieda (1998) os ambientes com corredeiras apresentam maiores abundâncias e ou riquezas de invertebrados bentônicos comparado com ambientes de remanso características de $\mathrm{P} 2$ e $\mathrm{P} 3$. 
Aplicação de métodos físicos, químicos e biológicos na avaliação da qualidade das águas em áreas de aproveitamento hidroelétrico da bacia do Rio São Tomás, Município de Rio Verde - Goiás Sandro Morais Pimenta, Alfredo Palau Peña, Patrícia Silva Gomes

TABELA5: Distribuição dos invertebrados bentônicos e sua ponderação quanto ao Valor de Tolerância a Poluição nos 5 pontos amostrados na bacia do rio São Tomás, município de Rio Verde -Goiás.

\begin{tabular}{|c|c|c|c|c|c|c|c|}
\hline \multicolumn{2}{|c|}{ Táxons } & \multirow{2}{*}{$\begin{array}{c}\text { Ponto } 1 \\
50\end{array}$} & \multirow{2}{*}{$\begin{array}{c}\text { Ponto } 2 \\
0\end{array}$} & \multirow{2}{*}{$\begin{array}{c}\text { Ponto } 3 \\
10\end{array}$} & \multirow{2}{*}{$\begin{array}{c}\text { Ponto } 4 \\
0\end{array}$} & \multirow{2}{*}{$\begin{array}{c}\text { Ponto } 5 \\
0\end{array}$} & \multirow{2}{*}{$\begin{array}{c}\text { VTP } \\
4\end{array}$} \\
\hline \multirow{3}{*}{ Ephemeroptera } & Baetidae & & & & & & \\
\hline & Baetidae & 120 & 0 & 0 & 0 & 0 & 4 \\
\hline & Leptohyphidae & 20 & 0 & 20 & 0 & 0 & 4 \\
\hline \multirow{3}{*}{ Trichoptera } & Hydroptilidae & 10 & 0 & 0 & 0 & 0 & 4 \\
\hline & Philopoamidae & 0 & 0 & 10 & 0 & 0 & NA \\
\hline & Hydropsychidae & 0 & 0 & 0 & 10 & 0 & 4 \\
\hline \multirow{3}{*}{ Diptera } & Chironomidae & 300 & 50 & 0 & 90 & 270 & 7 \\
\hline & Ceratopogonidae & 0 & 0 & 0 & 0 & 10 & 6 \\
\hline & Simuliidae & 10 & 0 & 10 & 0 & 0 & 6 \\
\hline Collembola & Collembola & 0 & 0 & 0 & 10 & 0 & NA \\
\hline Heteroptera & Naucoridae & 10 & 10 & 0 & 0 & 0 & NA \\
\hline \multirow{2}{*}{ Coleoptera } & Elmidae & 10 & 100 & 0 & 50 & 0 & 4 \\
\hline & Hydrophilidae & 0 & 0 & 10 & 0 & 0 & NA \\
\hline Anellida & Oligochaeta & 20 & 10 & 0 & 10 & 20 & NA \\
\hline Nematoda & Nematoda & 0 & 0 & 10 & 0 & 10 & NA \\
\hline Microcrustacea & Ostracoda & 0 & 0 & 10 & 40 & 0 & NA \\
\hline
\end{tabular}

NA- Não foi possível identificar o VTP (Valor de Tolerância a Poluição)

TABELA 6: Classificação dos Táxons quanto sua bioindicação a tolerância dos ambientes segundo Callisto et al (2004-b) nos 5 pontos amostrados na bacia do rio São Tomás, município de Rio Verde -Goiás.

\begin{tabular}{|c|c|c|c|c|c|c|}
\hline BIOINDICADORES & Táxons & Ponto 1 & Ponto 2 & Ponto 3 & Ponto 4 & Ponto 5 \\
\hline \multirow{3}{*}{ Intolerantes } & Trichoptera & 1 & 0 & 1 & 1 & 0 \\
\hline & Plecoptera & 0 & 0 & 0 & 0 & 0 \\
\hline & Ephemeroptera & 3 & 0 & 2 & 0 & 0 \\
\hline \multicolumn{2}{|c|}{ Somatória- Intolerantes } & 4 & 0 & 3 & 1 & 0 \\
\hline \multirow{3}{*}{ Tolerantes } & Coléoptera & 1 & 1 & 1 & 1 & 0 \\
\hline & Heteroptera & 1 & 1 & 0 & 0 & 0 \\
\hline & Odonata & 0 & 0 & 0 & 0 & 0 \\
\hline \multicolumn{2}{|c|}{ Somatória - Tolerantes } & 2 & 2 & 1 & 1 & 0 \\
\hline \multirow{2}{*}{ Resistentes } & Diptera & 2 & 1 & 1 & 2 & 2 \\
\hline & Oligochaeta & 1 & 1 & 0 & 1 & 1 \\
\hline \multicolumn{2}{|c|}{ Somatória - Resistentes } & 3 & 2 & 1 & 3 & 3 \\
\hline
\end{tabular}

\subsection{Análises Físico-Químicas}

Os resultados das análises dos parâmetros físico-químicos e biológicos das águas na área de influência estão descritos na tabela a seguir (TAB. 7). São apresentados os valores obtidos na avaliação das amostras coletadas os valores permitidos pela Resolução 357/05 do CONAMA, e o tratamento estatístico paramétrico preliminar.

A amostragem realizada apresentou média harmônica de 73,19 para o parâmetro Turbidez, os pontos P2, P3, P4 ultrapassaram os valores definidos pela
Resolução 357/05 CONAMA. O coeficiente de variação entre os pontos amostrados foi de 109,42\%, determinando uma variação considerável do parâmetro nos pontos de amostragem. Este parâmetro apresentou freqüência absoluta com P2 e P4 com o mesmo valor para turbidez. O parâmetro Cor na amostragem apresentou média harmônica de 265,96, demonstrando alteração quanto aos limites permitidos pelo CONAMA. O coeficiente de variação entre os pontos de coleta foi de $96,10 \%$, indicador de alta variação do parâmetro entre os pontos de amostragem, este parâmetro não apresentou freqüência (FIG. 8). 
Aplicação de métodos físicos, químicos e biológicos na avaliação da qualidade das águas em áreas de aproveitamento hidroelétrico da bacia do Rio São Tomás, Município de Rio Verde - Goiás Sandro Morais Pimenta, Alfredo Palau Peña, Patrícia Silva Gomes

TABELA 7: Resultados das análises físico-químicas na área de implantação dos PAH, no rio São Tomás Período Chuvoso - Coleta 17/12/2008.

\begin{tabular}{|c|c|c|c|c|c|c|c|c|c|c|}
\hline \multirow{2}{*}{ PARÂMETROS } & \multicolumn{5}{|c|}{ PONTOS } & \multirow{2}{*}{$\begin{array}{c}\text { Conama } \\
357 / 05\end{array}$} & \multirow{2}{*}{ Media } & \multirow{2}{*}{ Freq. } & \multirow{2}{*}{$\begin{array}{l}\text { Desvio } \\
\text { Padrão }\end{array}$} & \multirow{2}{*}{$\begin{array}{c}\text { Cof. } \\
\text { Variação (\%) }\end{array}$} \\
\hline & P1 & P2 & P3 & P4 & P5 & & & & & \\
\hline Turbidez (uT) & 54,50 & 199 & 152 & 199 & 30 & 100 & 73,19 & 2 & 80,09 & 109,42 \\
\hline Cor Verdadeira (mgPt/1) & 205 & 728 & 395 & 594 & 120 & 75 & 265,96 & - & 255,60 & 96,10 \\
\hline Temperatura $\left({ }^{\circ} \mathrm{C}\right)$ & 24,70 & 24,80 & 24,90 & 26 & 25,10 & - & 25,09 & - & 0,52 & 2,09 \\
\hline $\mathrm{Ph}$ & 6,96 & 6,94 & 6,93 & 7,01 & 7,01 & $6,0-9,0$ & 6,97 & 2 & 0,04 & 0,55 \\
\hline C.E $(\mu \mathrm{S} / \mathrm{cm})$ & 38,70 & 50,30 & 55,40 & 46,60 & 99,20 & - & 52,46 & - & 23,80 & 45,37 \\
\hline $\operatorname{STD}(\mathrm{mg} / \mathrm{l})$ & 18 & 24 & 26 & 22 & 47 & 500 & 24,70 & - & 11,35 & 45,94 \\
\hline $\mathrm{OD}(\mathrm{mg} / \mathrm{l})$ & 7,80 & 7,20 & 8 & 7,50 & 5 & 4 & 6,89 & - & 1,21 & 17,59 \\
\hline $\mathrm{DBO}(\mathrm{mg} / \mathrm{l})$ & 0,60 & 1,40 & 2,30 & 1,20 & 0,60 & 5 & 0,94 & - & 0,70 & 74,57 \\
\hline $\mathrm{DQO}(\mathrm{mg} / \mathrm{l})$ & 1 & 2 & 3 & 1,78 & 1 & 5 & 1,47 & 2 & 0,83 & 56,31 \\
\hline Fósforo Total (mg/l) & 0,39 & 0,51 & 0,36 & 0,58 & 0,15 & 0,05 & 0,32 & - & 0,16 & 51,52 \\
\hline Nitrogênio Total (mg/) & 3,36 & 3,92 & 3,36 & 3,36 & 3,92 & NA & 3,56 & 3 & 0,31 & 8,61 \\
\hline Coliformes Totais (NMP/100ml) & 280 & 280 & 750 & 1500 & 1500 & 5000 & 509,71 & 2 & 613,20 & 120,30 \\
\hline $\begin{array}{l}\text { Coliformes Termotolerantes } \\
\text { (NMP/100ml) }\end{array}$ & 150 & 280 & 750 & 1500 & 930 & 1000 & 375,56 & - & 541,27 & 144,12 \\
\hline
\end{tabular}

N.A - Não aplicável

NMP - Número Mais Provável

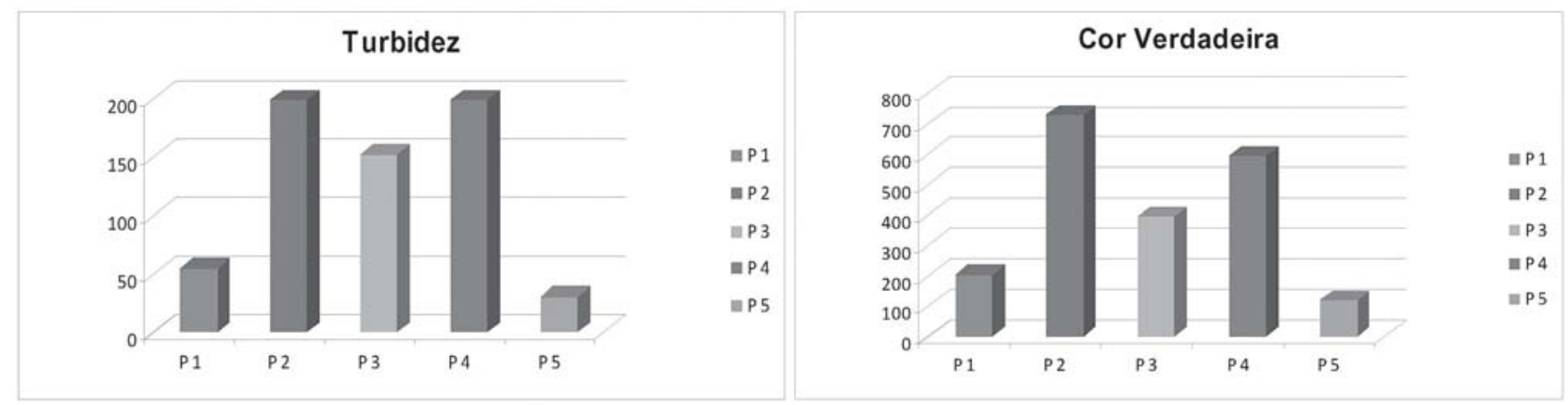

FIGURA 8: Variação quantitativa dos pontos de amostragem para os parâmetros turbidez e cor.

O parâmetro Temperatura apresentou média harmônica de 25,09. Não há parâmetros de temperatura estabelecidos pela Resolução CONAMA 357/05. O coeficiente de variação entre os pontos de coleta foi de 2,09\%, indicando mínima variação do parâmetro entre os pontos de amostragem. Apenas o $\mathrm{P} 4$ apresentou temperatura um pouco mais alta que os outros pontos, de $26^{\circ} \mathrm{C}$. Este parâmetro não apresentou freqüência. A amostragem do parâmetro pH apresentou média harmônica de 6,92, estando assim, todos os pontos amostrados dentro dos valores permitidos pela CONAMA 357/05. O coeficiente de variação pode ser considerado baixíssimo de 0,55\%. O pH apresentou freqüência com entre P4 e P5 (FIG. 9).

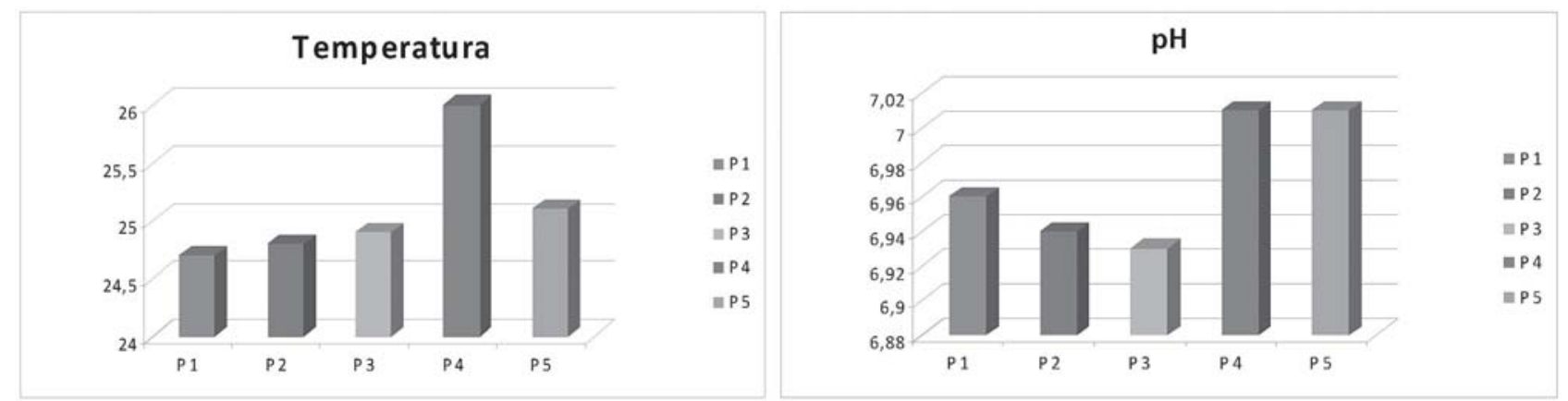

FIGURA 9: Variação quantitativa dos pontos de amostragem para os parâmetros temperatura e pH. 
A média harmônica da C.E - Condutividade Elétrica na amostragem foi de 52,46. Não existem referências aos valores máximos e mínimos na Resolução do CONAMA 357/05. O P5 apresentou um maior valor, de 99,20. O coeficiente de variação foi médio, 45,37\%, entre os pontos. Os STD - Sólidos Totais
Dissolvidos apresentaram média harmônica de 24,70, sendo que nenhum ponto apresentou valores acima do permitido pelo CONAMA. O P5 apresentou o maior valor de STD de $47 \mathrm{mg} / \mathrm{L}$. O coeficiente de variação entre os pontos amostrados foi de 45,94\%, demonstrando média variação do parâmetro (FIG. 10).

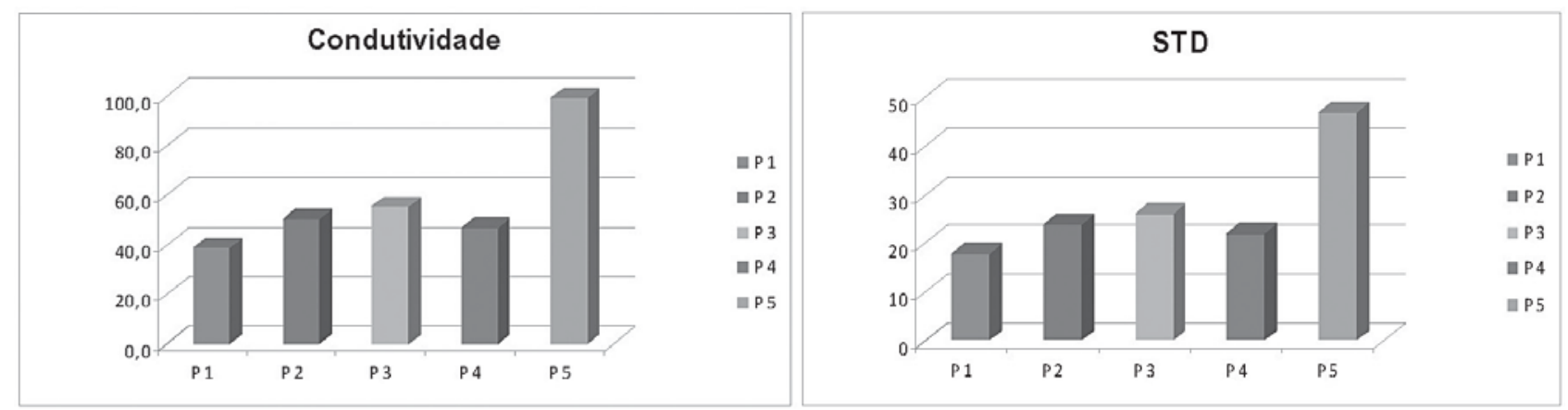

FIGURA 10: Variação quantitativa dos pontos de amostragem para os parâmetros C.E e STD.

Os valores obtidos na avaliação da amostragem para Oxigênio Dissolvido nos pontos determinaram a média harmônica do parâmetro de 6,89. Os valores encontrados estão acima dos valores mínimos definidos pela Resolução CONAMA 357/05. Não há no texto da resolução referências a valores máximos de OD. O coeficiente de variação do parâmetro foi de 17,59\%, demonstrando baixa variação entre as amostras. $\mathrm{O}$ parâmetro DBO - Demanda Bioquímica de Oxigênio, apresentou média harmônica de 0,94 , sendo que, nenhum dos pontos apresentou amostras com DBO acima do valor máximo definido pelo CONAMA. O coeficiente de variação do parâmetro apresentou variações razoáveis de 74,57\%, entre os pontos amostrados, o maior valor apresentado foi no P3 (2,30 mg/L). Os valores apresentaram freqüência entre P1 e P5 (FIG. 11).

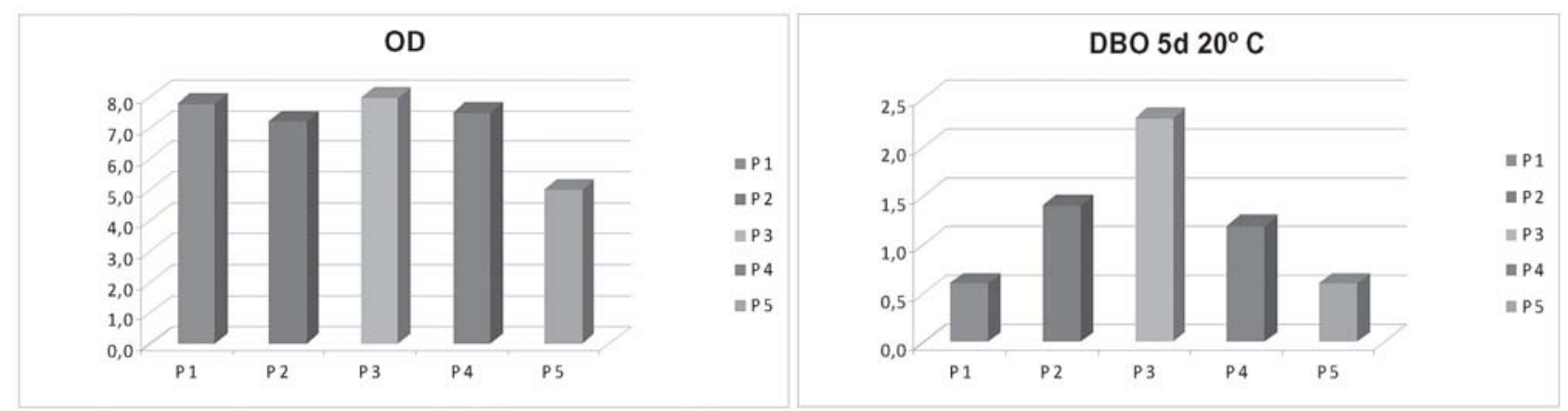

FIGURA 11: Variação quantitativa dos pontos de amostragem para os parâmetros O.D e DBO.

A DQO - Demanda Química de Oxigênio apresentou média harmônica de 1,47, a Resolução 357 do CONAMA determina valores máximos de DQO de 5 $\mathrm{mg} / \mathrm{L}$. O coeficiente de variação da amostragem foi de $56,31 \%$, um coeficiente médio. O maior valor foi apresentado pelo P3 (3,00 mg/L), ocorreu freqüência entre P1 e P5. A média harmônica do parâmetro Fósforo
Total foi de 0,32. O parâmetro determinado pela Resolução 357 do CONAMA é de 0,050 mg/L, estando alguns pontos amostrados acima da norma estabelecida. O coeficiente de variação da amostragem foi de 51,52\%, um coeficiente médio, não demonstrando variações significantes entre os pontos. Não apresentou freqüência nos pontos amostrados (FIG. 12). 


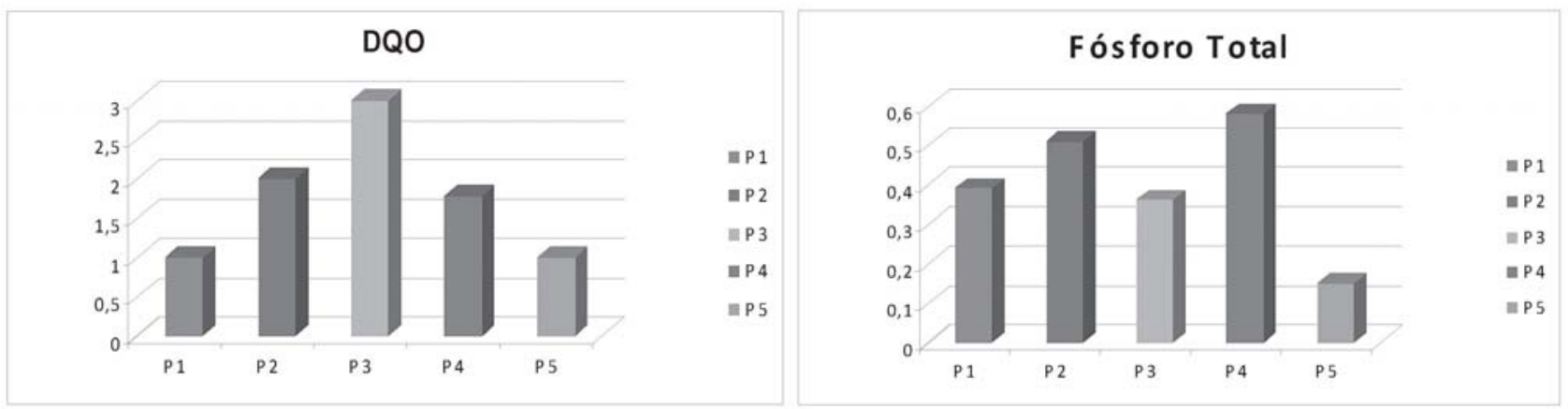

FIGURA 12: Variação quantitativa dos pontos de amostragem para os parâmetros DQO e Fósforo Total.

A média harmônica do parâmetro Nitrogênio Total foi de 3,56. Não há parâmetro determinado pela Resolução 357 do CONAMA. O coeficiente de variação da amostragem foi de 8,61\%, um coeficiente mínimo, não demonstrando variações significantes entre os pontos. Apresentou freqüência nos pontos amostrados P1, P3 e P4. A amostragem de Coliformes To- tais nos pontos definidos apresentou média harmônica alta de 509,71, porém todos os valores estão dentro dos limites permitidos pelo CONAMA. O coeficiente de variação foi de $120,30 \%$, evidenciando variação acentuada do parâmetro entre os pontos de coleta. A amostragem apresentou freqüência entre P1 e P2, e também em P4 e P5 (FIG. 13).

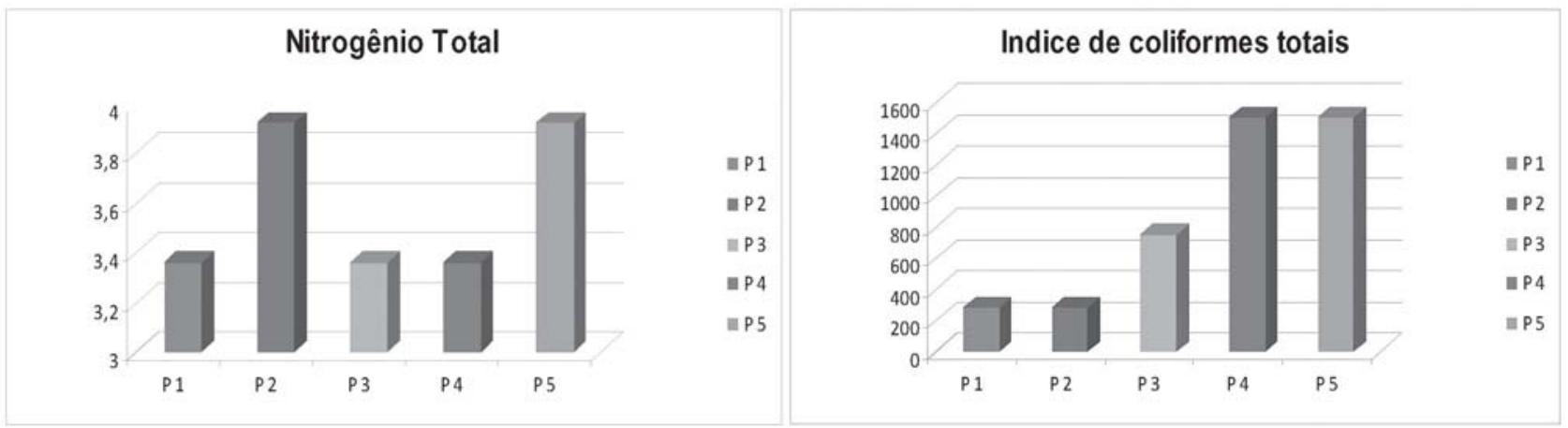

FIGURA 13: Variação quantitativa dos pontos de amostragem para os parâmetros Nitrogênio e Coliformes Totais.

Os valores obtidos na amostragem de Coliformes Termotolerantes apresentaram média harmônica de 375,56. Todos os valores estão dentro do estabelecido pela Resolução 357/05 do CONAMA. O coefici- ente de variação do parâmetro foi de 144,12\%, que representa um coeficiente alto. O parâmetro não apresenta freqüência (FIG. 14).

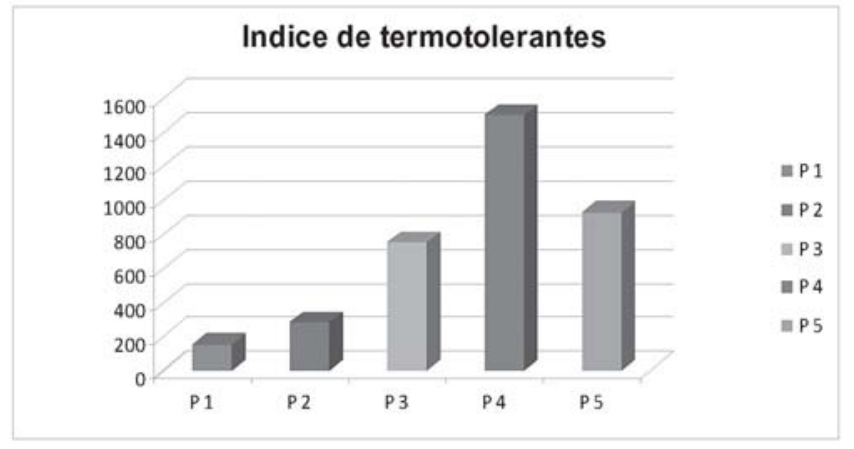

FIGURA 14: Variação quantitativa dos pontos de amostragem para o parâmetro Coliformes Termotolerantes 
Aplicação de métodos físicos, químicos e biológicos na avaliação da qualidade das águas em áreas de aproveitamento hidroelétrico da bacia do Rio São Tomás, Município de Rio Verde - Goiás Sandro Morais Pimenta, Alfredo Palau Peña, Patrícia Silva Gomes

\subsection{IQA - Índice de Qualidade de Água}

A TAB. 8 abaixo apresenta os resultados do
IQA para os 05 pontos de amostragens espacializados nas áreas dos PAHs. A classificação adotada segue os critérios estabelecidos pela CETESB.

TABELA 8: Avaliação do IQA para os pontos de Amostragem

\begin{tabular}{ccc}
\hline PONTO & IQA & CLASSIFICAÇ̃̃O \\
\hline P1 & 67 & Boa \\
P2 & 52 & Boa \\
P3 & 52 & Boa \\
P4 & 50 & Aceitável \\
P5 & 63 & Boa \\
\hline
\end{tabular}

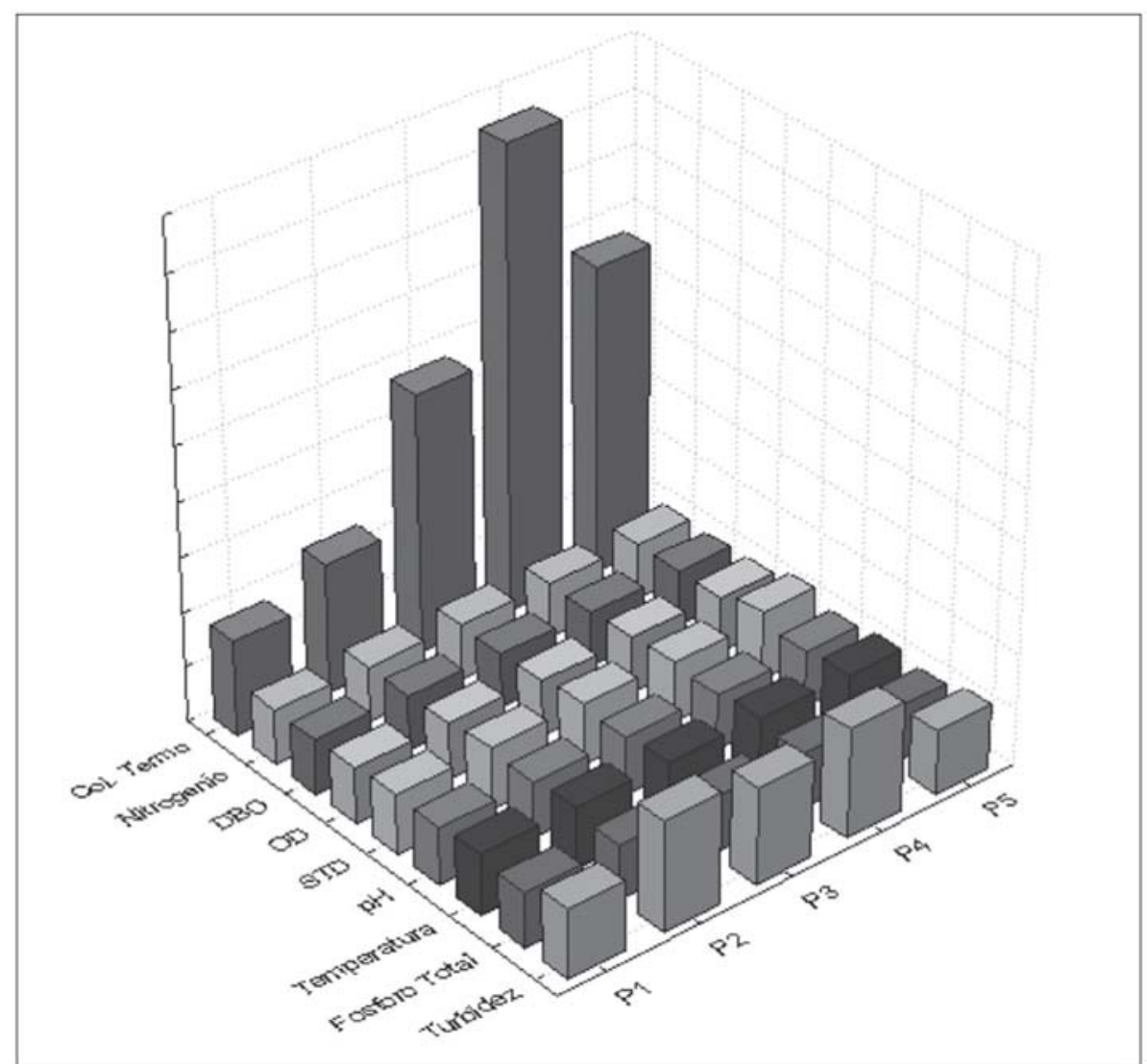

FIGURA 15: Representação da variação nos parâmetros de qualidade componentes do IQA, nos pontos amostrados na área dos PAH.

Os parâmetros C.E. e S.T.D. tendem a diminuir suas concentrações no período chuvoso. Ao analisar os gráficos dos parâmetros C.E e S.T.D é possível visualizar a correlação entre esses parâmetros, apresentando gráficos com distribuição qualitativa semelhante entre os pontos.

No período chuvoso o parâmetro turbidez e cor apresentaram anomalias acima dos Valores Máximos Permitidos - VMP estabelecidos pelo CONAMA.
Ao longo da drenagem do rio São Tomás são visíveis corredeiras e quedas d'água que podem proporcionar esse aumento da turbidez e da cor na época chuvosa, por meio do aumento de material em suspensão possivelmente originários da área de influência e dos usos do solo.

O cloreto apresenta maiores concentrações na época chuvosa. As possíveis fontes de alterações nesses parâmetros são os esgotos domésticos sanitários 
Aplicação de métodos físicos, químicos e biológicos na avaliação da qualidade das águas em áreas

de aproveitamento hidroelétrico da bacia do Rio São Tomás, Município de Rio Verde - Goiás

Sandro Morais Pimenta, Alfredo Palau Peña, Patrícia Silva Gomes

oriundos da área urbana e/ou fertilizantes e insumos agrícolas utilizados nas atividades agropastoris da região.

Os Pontos P4 e P5 selecionados apresentaram as maiores incidência de variações e os valores mais acentuados dos parâmetros físico-químicos de qualidade, o P4 apresentou o IQA mais baixo (aceitável).

É possível prever que nos pontos avaliados, a condição sanitária será agravada no período seco, apresentando as maiores elevações nos parâmetros de qualidade em função da redução da vazão das drenagens, favorecendo a concentração dos elementos.

\section{CONSIDERAÇÕES}

O conjunto de métodos de avaliação de qualidade de água utilizados neste estudo (as análises dos parâmetros de qualidade de água, o tratamento estatístico dos valores identificados na amostragem, a aplicação do protocolo de avaliação ecológica rápida de habitats, a utilização do IQA e dos bioindicadores) auxiliou na caracterização da qualidade das águas do rio São Tomás e identificou os pontos com maiores alterações.

O processo de uso e ocupação do solo nas drenagens da Bacia do São Tomás contribuiu de forma significativa para as alterações na qualidade da água, seja por lançamentos de efluentes in-natura e resíduos nas drenagens da bacia ou pela existência de áreas desprovidas de cobertura vegetal por atividades agropastoris com os conseqüentes usos de agrotóxicos e adubos químicos.

No período chuvoso constatou-se um maior carreamento de partículas do solo para o leito do rio São Tomás e seus tributários. Aliado a esse fator, temse ainda a presença das atividades agropastoris em suas vertentes, que também contribuem para o carreamento de materiais para o leito do curso de água. Esses fatores, em conjunto, possivelmente provocaram as alterações nos parâmetros de qualidade da água.

Os resultados do protocolo de avaliação ecológica rápida, associado à avaliação de bioindicadores apontaram as alterações ambientais mais visíveis em P4 e P5, reforçando o que foi detectado nas análises físico-químicas realizadas indicando coerência entre os métodos de avaliação. A condição natural com presen- ça de espécies bioindicadoras de qualidade ambiental foi identificada no P1, seguido dos demais pontos P3, P4, P2 até chegar a uma condição ambiental alterada no P5 com presença somente de espécies indicadoras de ambiente alterado. Porém ao longo dos trechos avaliados os métodos aplicados indicaram no contexto geral boa qualidade da água amostrada.

A utilização do conjunto de métodos de avaliação da qualidade da água e a correlação entre estes métodos propiciaram a melhor interpretação dos resultados com a elaboração de uma avaliação mais consolidada para determinar a qualidade da água nos pontos amostrados.

Deve-se ressaltar que todas as áreas de influência direta e indireta dos Pontos de Aproveitamento Hidrelétrico estudados possuem passivos ambientais gerados pelas atividades antrópicas, que contribuem de forma significativa para as alterações na qualidade da água, seja por áreas de preservação permanente desprovidas de cobertura vegetal, lançamentos de efluentes, ou por atividades agropastoris. Esta avaliação da qualidade da água gera a complexa reflexão sobre a ação antrópica no meio físico e nos recursos naturais.

Assim, recomenda-se: implantar marcos indicativos nos pontos de monitoramento de qualidade das águas realizado neste estudo com objetivo de facilitar as vistorias pertinentes, dar continuidade ao monitoramento dos parâmetros físico-químicos, a fim de manter os valores reais acertados aos estabelecidos pela Resolução CONAMA ñ ${ }^{357}$. Também possibilita identificar as alterações na qualidade da água relacionadas com o funcionamento de PCHs a partir da utilização de bioindicadores e do protocolo de avaliação ecológica.

\section{AGRADECIMENTOS}

Os autores agradecem a DBO Engenharia Ambiental e aos seus consultores técnicos, pela colaboração no desenvolvimento do trabalho.

\section{REFERÊNCIAS}

AGENCIA NACIONAL DE ENERGIA ELÉTRICAANEEL. Despacho no 249 de 02/02/2007: Aprovação 
Aplicação de métodos físicos, químicos e biológicos na avaliação da qualidade das águas em áreas de aproveitamento hidroelétrico da bacia do Rio São Tomás, Município de Rio Verde - Goiás Sandro Morais Pimenta, Alfredo Palau Peña, Patrícia Silva Gomes

dos Estudos de Inventario Hidrelétrico Simplificado do rio São Tomás localizado na sub-bacia nº6, bacia hidrográfica do rio Paranaíba, no Estado de Goiás, 2007.

AGENCIA NACIONAL DE ENERGIA ELÉTRICA ANEEL. Resolução $n^{\circ} 394$ de 04/12/1998: Estabelece os procedimentos gerais para registro e aprovação de estudos de viabilidade e projeto básico de empreendimentos de geração hidrelétrica, assim como da autorização para exploração de centrais hidrelétricas até 30 MW e dá outras providências; Brasília, 1998.

ANDREOLI, C.V, CARNEIRO. C. Gestão Integrada de Mananciais de Abastecimento Eutrofizados. Curitiba: Sanepar Finep, 2005.

ASSOCIAÇÃO BRASILEIRA DE NORMAS TÉCNICAS. NBR 9898/1987: Preservação e técnicas de amostragem de efluentes líquidos e corpos receptores; Rio de Janeiro, 1987.

BISPO, P.C.; OLIVEIRA,L.G.; CRISCI,V.L.; SILVA, M.M. 2001. A pluviosidade como fator de alteração da entomofauna bentônica (Ephemeroptera, Plecoptera e Trichoptera) em córregos do Planalto Central do Brasil. Acta Limnol.Bras., v 13,.2,p.1-9.

BONNET B.R.P. Relações Entre a Qualidade da Água e Uso do Solo em Bacias Hidrográficas no Cerrado Brasileiro: Aspectos físicos e sociais e proposições de diretrizes. 95f. Tese. (Doutorado em Ciências Ambientais). CIAMB/UFG. Goiânia. 2007.

CALLISTO, M. \& MORENO, P. 2006. Bioindicadores como ferramenta para o manejo, gestão e conservação ambiental. II Simpósio Sul de Gestão e Conservação Ambiental - 21 a 25/08/2006 - URI/Campus de Erechim - Erechim/RS.

CALLISTO, M; FERREIRA, W.R.; MORENO,P.; GOULART, M. \& PETRUCIO, M. 2002. Aplicação de um protocolo de avaliação rápida da diversidade de habitats em atividades de ensino e pesquisa (MG) -RJ). Acta Limnológica brasileira, 34: 91-97.
CALLISTO, M; GONÇALVES, JR., J.R.; MORENO,P. 2004(a). Invertebrados aquáticos como bioindicadores. In: Navegando o Rio das Velhas das Minas aos Gerais. Belo Horizonte. UFMG. v1, p 1-12.

CALLISTO, M; GOULART, M.; MEDEIROS, A.O.; MORENO,P.; ROSA,C.A. 2004(b). Diversity assessment of benthic macroinvertebrates, yeasts and microbiological indicators along a longitudinal gradient in Serra do Cipó, Brazil. Braz. J. Biol., v.61,n. 2,p 259-266.

CARMO, M.S.; BOAVENTURA, G. R.; OLIVEIRA, E.C. Geoquímica das Águas da Bacia do Rio Descoberto. Química Nova Vol. 28 nº 4, Brasília - DF, Brasil, 2005.

CHALAR, G. 1994. Composicíon y abundancia Del zoobentos Del Arroyo Toledo (Uruguay) y su relación com La calidad de água. Rev. Chil. Hist. Nat., v.67, p. 129-141.

CONSELHO NACIONAL DO MEIO AMBIENTE, Resolução CONAMA 357/05: Estabelecer a classificação das águas, doces, salobras e salinas do Território Nacional. Brasília-DF, 2005.

CONSELHO NACIONAL DO MEIO AMBIENTE, Resolução $N^{\circ}$ 279, de 27 de Junho de 2001, BrasíliaDF, 2001.

GALINKIN, Maurício. GeoGoiás 2003, ed; Goiânia: Ambiental de Goiás: Fundação CEBRAC: PNUMA: SEMARH, 2003.

KIKUCHI, R.M. \& UIEDA, V.S. 1998. Composição da comunidade de invertebrados de um ambiente lótico tropical e sua variação espacial e temporal. p. 157-173. In: Nessimian, J.L. \& Carvalho, E.A.L. (eds): Ecologia de insetos aquáticos. Series Oecologia Brasiliensis. Vol. 5 PPGE-UFRJ, Rio de Janeiro.

KING, K.W. 1993. Laboratory manual and ilustrated guide to orders of common Wyoming stream macroinvertebrates. Wyoming. Wyoming Departament of Environmental Quality. 
MONKOLSKI, A., HIGUTI, J., VIEIRA, L.A., MORMUL, R.P. \& SIDNEY, P.J., 2006. Invertebrados bentônicos com indicadores de qualidade da água do rio dos Papagaios - campo Mourão - PR. SaBios: Rev. Saúde e Biol., V.1, n. 1. p. 4-12.

PIMENTA, S.M. Avaliação físico-química da qualidade da água na bacia hidrográfica do Santo Antônio: Aparecida de Goiânia/GO. 79f. Dissertação (Mestrado em Geografia). IESA/UFG. Goiânia. 2008.

PIMENTA, S.M. Sistemas simplificados de tratamento de efluentes aplicados na redução dos impactos na qualidade da água nos mananciais de áreas urbanas. 88f. Monografia (Especialização em Gestão e Inovações Tecnológicas na Construção). UFLA-MG. Lavras, 2006.

TUCCI, C.E.M. Hidrologia: Ciência e Aplicação. $2^{\circ}$. ed. Editora da Universidade UFRGS: ABRH, Porto Alegre. 2001.

VON SPERLING, M. Introdução à qualidade das águas e ao tratamento de esgotos. Belo Horizonte: DESA, 2005. 